\title{
NEM SÓ DE PÃO VIVE O HOMEM
}

\author{
Rodrigo da Cunha Pereira* \\ Cláudia Maria Silva**
}

\begin{abstract}
Resumo: Este artigo pretende contribuir com a discussão sobre as prerrogativas da paternidade sob o prisma da valorização das funções paternas, das limitações de direitos e da afirmação de deveres do pai. Uma polêmica instigante se instalou a partir da eclosão de demandas judiciais em que filhos denunciam o abandono afetivo, psíquico e moral de seus pais, pedindo reparação pelos danos causados, em processos que chegaram aos tribunais, Alguns entendem que o abandono afetivo deve ser reparado por meio de indenização pecuniária. Outros, com o argumento de que não se pode obrigar um pai a amar e a conviver com seu filho, se opõem à exigência de reparação por abandono. Argumentam que, uma vez cumprido o dever de prestar alimentos, o pai se desincumbiria de suas obrigações perante o filho. Entretanto, nem só de pão vive o homem...
\end{abstract}

Palavras-chave: paternidade, danos morais, afeto como valor jurídico, reparação.

Por razões culturais, sociais, políticas e ideológicas, a família mudou e o ordenamento jurídico vem buscando responder a essas mudanças. Sozinho, o elo biológico ou genético não sustenta a base familiar. $\mathrm{O}$ afeto, o respeito, a vontade de seguir juntos e o tratamento igualitário vêm se tornando o elo entre seus componentes. Como diz Oliveira (2002, p. 233):

\footnotetext{
* Presidente do Instituto Brasileiro de Direito de Família (IBDFAM), doutor em Direito Civil (UFPR), advogado em Belo Horizonte, especialista em Direito de Família, professor da $\mathrm{PUC} / \mathrm{MG}$, autor de vários livros.

** Advogada em Belo Horizonte, especialista em Direito de Família e membro do Instituto Brasileiro de Direito de Família (IBDFAM).

Recebido em 7 mar. 2006 e aprovado em 13 dez. 2006.
} 
A afetividade, traduzida no respeito de cada um por si e por todos os membros - a fim de que a família seja respeitada em sua dignidade e honorabilidade perante o corpo social - é, sem dúvida alguma, uma das maiores características da família atual.

Conforme proposto pela Constituição Federal de 1988, a base da família deve centrar-se na dignidade da pessoa humana e na solidariedade social, sendo que a relação paterno-filial assume destaque nas disposições sobre a temática da família. A proibição da discriminação entre os filhos, a previsão da paternidade socioafetiva deixam claro a preocupação com os filhos, como verdadeiros sujeitos de direito.

$\mathrm{Na}$ assunção de seus papéis de pais, os genitores não devem limitar seus encargos ao aspecto material, ao sustento. Alimentar o corpo, sim, mas também cuidar da alma, da moral, da psique. Essas são prerrogativas do "poder familiar" e, principalmente, da delegação de amparo aos filhos.

No meio jurídico e social se instalou a discussão acerca dos limites das obrigações e deveres dos pais com relação aos filhos, tanto no âmbito da sociedade conjugal quanto após seu desfazimento. Tal debate originou-se com algumas ações judiciais propostas por filhos pleiteando indenização por danos decorrentes do abandono afetivo de seus pais.

Entre tais decisões, destacamos o acórdão do Tribunal de Justiça de Minas Gerais, proferido em $1^{\circ}$ de abril de 2004, Apelação Cível $n^{\circ}$ 408.550-5, que fixou em 200 (duzentos) salários mínimos a indenização, conforme ementa abaixo transcrita:

EMENTA - INDENIZAÇÃO DANOS MORAIS - RELAÇÃO PATERNO-FILIAL - PRINCÍPIO DA DIGNIDADE DA PESSOA HUMANA - PRINCÍPIO DA AFETIVIDADE.

A dor sofrida pelo filho, em virtude do abandono paterno, que o privou do direito à convivência, ao amparo afetivo, moral e psíquico, deve ser indenizável, com fulcro no princípio da dignidade da pessoa humana. 


\section{(...)}

Trata-se de recurso de apelação interposto por A. B. F. - menor púbere representado por sua mãe - contra a sentença que, nos autos da ação de indenização por danos morais ajuizada contra seu pai, V. de P. F. de O., julgou improcedente o pedido inicial, ao fundamento de que inexistente o nexo causal entre o afastamento paterno e o desenvolvimento de sintomas psicopatológicos pelo autor.

Sustenta o apelante, em síntese, que o conjunto probatório presente nos autos é uníssimo ao afirmar a existência do dano resultante da ofensa causada pelo apelado. Afirma que a dor sofrida pelo abandono é profundamente maior que a irresignação quanto ao pedido revisional de alimentos requerido pelo pai. Aduz que o tratamento psicológico ao qual se submete há mais de dez anos advém da desestruturação causada pelo abandono paterno. Pugna, ao final, pelo provimento do recurso.

Contra-razões às fls. 105-407.

\section{$(\ldots$.}

No seio da família da contemporaneidade desenvolveu-se uma relação que se encontra deslocada para a afetividade. Nas concepções mais recentes de família, os pais de família têm certos deveres que independem do seu arbítrio, porque agora quem os determina é o Estado.

Assim, a família não deve mais ser entendida como uma relação de poder, ou de dominação, mas como uma relação afetiva, o que significa dar a devida atenção às necessidades manifestas pelos filhos em termos, justamente, de afeto e proteção.

Os laços de afeto e de solidariedade derivam da convivência e não somente do sangue.

No estágio em que se encontram as relações familiares e o desenvolvimento científico, tende-se a encontrar a harmonização entre o direito de personalidade ao conhecimento da origem genética, até como necessidade de concretização do direito à saúde e prevenção de doenças, e o direito à relação de parentesco, fundado no princípio jurídico da afetividade. 
O princípio da efetividade (sic) especializa, no campo das relações familiares, o macro-princípio da dignidade da pessoa humana (artigo $1^{\circ}$, III, da Constituição Federal), que preside todas as relações jurídicas e submete o ordenamento jurídico nacional.

No estágio atual, o equilíbrio do privado e do público pauta-se exatamente na garantia do pleno desenvolvimento da dignidade das pessoas humanas que integram a comunidade familiar.

No que respeita à dignidade da pessoa da criança, o artigo 227 da Constituição expressa essa concepção, ao estabelecer que é dever da família assegurar-lhe "com absoluta prioridade, o direito à vida, à saúde, à alimentação, à educação, ao lazer, à profissionalização, à cultura, à dignidade, ao respeito, à liberdade e à convivência familiar e comunitária", além de colocá-la "a salvo de toda forma de negligência, discriminação, exploração, violência, crueldade e opressão". Não é um direito oponível apenas ao Estado, à sociedade ou a estranhos, mas a cada membro da própria família.

Assim, depreende-se que a responsabilidade não se pauta tãosomente no dever alimentar, mas se insere no dever de possibilitar o desenvolvimento humano dos filhos, baseado no princípio da dignidade da pessoa humana.

No caso em comento, vê-se claramente, da cuidadosa análise dos autos, que o apelante foi, de fato, privado do convívio familiar com seu pai, ora apelado.

Até os seis anos de idade, A. B. F., ora apelante, manteve contato com seu pai de maneira razoavelmente regular. Após o nascimento de sua irmã, a qual ainda não conhece, fruto de novo relacionamento conjugal de seu pai, este afastou-se definitivamente. Em torno de quinze anos de afastamento, todas as tentativas de aproximação efetivadas pelo apelante restaram-se infrutíferas, não podendo desfrutar da companhia e dedicação de seu pai, já que este não compareceu até mesmo em datas importantes, como aniversários e formatura.

De acordo com o estudo psicológico realizado nos autos, constata-se que o afastamento entre pai e filho transformou-se em uma questão 
psíquica de difícil elaboração para A., interferindo nos fatores psicológicos que compõem sua própria identidade.

"É como se ele tentasse transformar o genitor em pai e, nesta árida batalha, procurasse persistentemente compreender porque o $\mathrm{Sr}$. Vicente não se posiciona como um pai, mantendo a expectativa de que ele venha a fazê-lo." (fls. 72).

"Neste contexto, ainda que pese o sentimento de desamparo do autor em relação ao lado paterno, e o sofrimento decorrente, resta a A., para além da indenização material pleiteada, a esperança de que o genitor se sensibilize e venha a atender suas carências e necessidades afetivas" (fls.74).

Assim, ao meu entendimento, encontra-se configurado nos autos o dano sofrido pelo autor, em relação à sua dignidade, a conduta ilícita praticada pelo réu, ao deixar de cumprir seu dever familiar de convívio e educação, a fim de, através da afetividade, formar laço paternal com seu filho, e o nexo causal entre ambos.

Desta forma, fixo a indenização por danos morais no valor equivalente a duzentos salários mínimos, ou seja, $\mathrm{R} \$$ 44.000,00, devendo ser atualizado monetariamente de acordo com a Tabela da Corregedoria Geral de Justiça e com juros de mora em 1\% ao mês, a contar da publicação do presente acórdão. Pelo que, condeno o apelado a pagar ao procurador do apelante, a título de honorários sucumbenciais, o valor relativo a $10 \%$ do valor da condenação em danos morais.

Com base em tais considerações, dou provimento ao recurso, para julgar procedente o pedido inicial, modificando a r. decisão ora objurgada.

\section{Custas pelo apelado."}

Submetida à apreciação do Superior Tribunal de Justiça (STJ), essa decisão foi, em dezembro de 2005, reformada integralmente, para liberar o pai de reparar o dano pelo abandono moral e afetivo do filho. Aquele Tribunal entendeu que não se pode obrigar o pai a amar, acolher, conviver com o filho, sobretudo quando ele honra a obrigação de pagar pensão alimentícia. Ou seja, basta o cumprimento 
do dever de sustento material. Essa decisão, entretanto, ainda não "transitou em julgado", isto é, não está encerrada definitivamente. Deverá ser submetida ainda ao Supremo Tribunal Federal (STF). Essa discussão é de grande relevância, permitindo uma reflexão sobre a função paterna e suas prerrogativas.

\section{Amor paterno, item opcional?}

É na família que o indivíduo nasce, se desenvolve, molda sua personalidade e se integra ao meio social. É na família que, no curso de sua vida, o indivíduo encontra conforto, amparo e refúgio para sua sobrevivência, formação e estruturação psíquica. A criança mantém uma relação direta de dependência com aqueles que, tendo concebido-a ou não, acolheram-na, se tornaram responsáveis pela continuação de sua existência e formação. A inserção em um núcleo familiar é importante para o desenvolvimento físico, psíquico e afetivo saudável da criança. Em geral, os responsáveis são os genitores, investidos do "poder familiar", outrora denominado "pátrio poder". Interessa-nos, aqui, o que foi estabelecido no entorno das recentes decisões judiciais sobre a responsabilidade civil do abandono paterno ou materno.

A função paterna sempre esteve atrelada à idéia de manutenção, de provimento, de poder sobre os demais componentes da família. Com o declínio do patriarcalismo e a luta por direito à igualdade entre homens e mulheres, essas concepções se alteraram. A figura paterna, entretanto, persiste relacionada à segurança, à proteção, ao acolhimento. Um elemento relevante para a afetividade e o crescimento saudável é a segurança que pode ser encontrada na família, entre os entes queridos, com os quais nos relacionamos desde o início de nossa existência. Consideramos, aqui, a diversidade de formas de famílias, pois para o sujeito interessa a inserção em um núcleo familiar, onde possa receber e dar amor, afeto, segurança e amparo. Para a criança, a segurança está vinculada à certeza do amor, à sua aceitação constante, ao acolhimento. A aceitação incondicional por parte dos pais é um elemento importante do amor. 
O vínculo da mãe com o filho se inicia com total intimidade e o elo entre pai e filho é de aceitação, de assunção de uma responsabilidade. O pai recebe e acolhe o filho como seu. Tal união transcende, então, o laço vital para configurar uma aceitação interior do filho. Ao assumir a paternidade, o pai aceita, sobretudo, a responsabilidade de dirigir e assegurar a vida do filho. Em outras palavras, a paternidade é uma função exercida e também um "serviço". Por isso não podem ser desprezadas ou ignoradas as situações em que a função paterna não é atributo exclusivo dos pais biológicos, embora na maioria das vezes haja coincidência.

Mesmo em situações de inexistência ou fim de uma conjugalidade, o pai representa a "autoridade" para o filho e para o fortalecimento da mãe perante o filho. Como escreve Juritsch (1970, p. 86):

O homem não é exigido, apenas, como genitor; ele se relaciona à mãe e ao filho também na sua qualidade de pai. A sua presença é necessária para o amadurecimento harmônico da relação mãe-filho, e para o desenvolvimento integral deste. A sadia relação mãe-filho, a dedicação carinhosa da mãe pelo filho, desenvolve-se em comunhão com o pai; ela recebe um fulgor especial com a aceitação do filho, desde o início, por parte do pai.

É fácil pensar na imagem de um pai conduzindo seu filho à escola, segurando-o pela mão. O filho, confiante, irradia segurança ao ser conduzido seguramente pelo pai, certo de que nada de mau lhe poderá acontecer. Fundem-se nessa imagem a segurança, a direção e o acompanhamento do pai, para o filho que o observa no dia-a-dia, referência e exemplo. Rubem Alves (2002, p. 37) bem o diz:

Pai é alguém que, por causa do filho, tem sua vida inteira mudada de forma inexorável. Isso não é verdadeiro do pai biológico. É fácil demais ser pai biológico. Pai biológico não precisa ter alma. Um pai biológico se faz num momento. Mas há um pai que é um ser da eternidade: aquele cujo coração caminha por caminhos fora do seu corpo. Pulsa, secretamente, no corpo do seu filho (muito embora o filho não saiba disso). 
A transferência de valores com a inserção do filho na vida social ocorre por meio da convivência e do afeto. E o exercício da função paterna nunca poderá estar atrelado, unicamente, ao suprimento das necessidades materiais do filho. A supressão dessa função causa ao filho, especialmente na infância, prejuízos psíquicos, morais e afetivos, que, só com dificuldades e sofrimentos, poderão ser reparados no futuro. No caso judicial aqui adotado como referência, a paternidade foi inicialmente exercida, em sua plenitude. $\mathrm{Na}$ primeira infância, o filho desfrutou da segurança, da proteção do pai ao conduzi-lo pela mão, rumo à escola e à vida. Sentiu a presença do pai e almejou que ele ali permanecesse. Houve, entretanto, o corte paterno, a negativa da perpetuação do afeto e de todos os atributos próprios do pai. Tratou-se de abandono e de rejeição. O filho buscou o pai incessantemente, demandando a continuidade do amor, do afeto, de sua presença e participação, em momentos importantes de seu desenvolvimento. E não mais encontrou aquele que um dia foi seu pai.

Ao recorrer à Justiça, esse filho recebeu do Tribunal de Justiça de Minas Gerais (TJMG) uma decisão favorável. A instância acima — o Superior Tribunal de Justiça (STJ) —, entretanto, entendeu que a solução de seu problema não seria a indenização pelo abandono afetivo, já que não há previsão legal específica, mas destituição do poder familiar. Em outras palavras, deveria ele pleitear a legitimação da supressão da figura paterna, retirando de seu genitor o título de pai. O filho muito buscou, extrajudicialmente, a continuidade do amor e do acolhimento de seu pai. A hipótese de esse filho recorrer ao Judiciário para banir a figura paterna e suas prerrogativas é impensável. Além de que essa "solução" significaria premiar o pai "abandônico", que, com a chancela judicial, se desincumbiria do dever de convivência, legalmente previsto e frontalmente violado.

Demasiadamente simples é a conclusão de que não se pode compensar a falta de amor ou obrigar a amar, como decantado pelo "craque" argentino Diego Armando Maradona, ao ser acionado judicialmente pelo filho italiano, diante da falta de atenção familiar, difamação e danos morais. Corolário do dever de sustento, é o dever 
de convivência familiar, previsto constitucionalmente (Art. 227, Constituição da República), não se esgotando na garantia da presença física, na coexistência, com ou sem coabitação. A obrigatoriedade da presença paterna não é apenas física, nem somente ligada à manutenção material.

Nesse sentido, tem-se a previsão contida nos incisos I e II do Art. 1.634, acerca do dever dos pais com relação aos filhos menores, de "dirigir-lhes a criação e educação", bem como "tê-los em sua companhia e guarda". Tais deveres paternos não guardam relação com o suprimento das necessidades materiais que se faz por meio do pagamento de pensão alimentícia. A lei é muito clara ao impor aos pais a companhia, a guarda, a direção de sua educação. E, se tais deveres são descumpridos em razão da ausência e/ou recusa paterna, estamos diante de nítidos atos ilícitos, gerando o dever de indenizar diante dos sérios danos que causam.

A supremacia dos pais - sobretudo do pai - sobre os filhos, tal como ocorria no Direito Romano, há muito foi erradicada. A Constituição da República e as legislações infra-constitucionais propugnam o tratamento prioritário a ser dispensado aos filhos, notadamente quando menores, seres em formação. Assim, deve ser questionada a contraposição entre a liberdade dos pais em acolher e amar os filhos e o direito dos filhos serem recebidos e amados por seus pais. A partir da averiguação de que o filho foi amado e manifesta necessidade e desejo de assim permanecer, não podemos pensar como faculdade do pai atender ou não a esse anseio.

Recente decisão do Tribunal de Justiça do Rio de Janeiro (TJRJ), que precedeu ao posicionamento do STJ, também negou a pretensão indenizatória em decorrência do abandono afetivo, valendo-se do argumento de que "por óbvio, ninguém está obrigado a conceder amor ou afeto a outrem, mesmo que seja filho". ${ }^{1}$ Esse posicionamento jurisprudencial, em síntese, também relegou o amor à esfera da moral individual e decantou que a assistência afetiva ou moral não pode ser exigida, nem gerar ressarcimento. Ao comentar a mencionada decisão, a professora Maria Celina Bodin de Moraes faz 
uma incursão ao novo enfoque da responsabilidade civil e conclui (2005, p. 54-55):

A responsabilidade civil, na atualidade, preocupa-se com a vítima e com os danos por ela sofridos, quase independentemente das razões de quem os causou. Ressarcíveis não são os danos causados mas, sim, os danos sofridos, e o olhar do Direito volta-se totalmente para proteção da vítima. Se o pai não tem culpa de não amar sua filha, tem a culpa de tê-la negligenciado. Assim, como se verá, o pai deve arcar com a responsabilidade por tê-la abandonado, por não ter convivido com ela, por não the ter educado, todos esses deveres impostos por lei.

Se a convivência, o acompanhamento, enfim, o amor paterno fossem opcionais, a lei não estabeleceria tais deveres, a serem cumpridos mesmo à margem do desejo do pai. A resistência ao acolhimento das pretensões indenizatórias decorrentes da rejeição paterna e do descumprimento do dever de convivência explica-se, em parte, pelo temor em vir a se instituir uma "indústria do dano moral" e uma monetarização do afeto. Não se trata, entretanto, de dar preço ao amor, mas de lembrar a esses pais responsabilidades na formação da personalidade e na garantia da dignidade dos filhos que geraram.

Afinal, se uma criança veio ao mundo - desejada ou não, planejada ou não - os pais devem arcar com a responsabilidade que esta escolha (consciente ou não) lhes demanda. (Teixeira, 2005, p. 156)

A preocupação dos magistrados e de outros opositores deveria ser a criação de mecanismos para reduzir o abandono afetivo, especialmente de filhos menores. A reparação do dano ganharia, primordialmente, um caráter punitivo, sancionatório, desestimulando condutas semelhantes e servindo como alerta. É relevante investigar se, de fato, ocorre o exercício de uma paternidade responsável, incluindo mais do que o adimplemento alimentar.

Se não se pode valorar o amor, ou punir pelo desamor, é inaceitável premiar a omissão de pais que geram filhos e lhes negam a convivência, o afeto e outros atributos necessários à formação da 
personalidade. Esses pais não poderiam ficar com a certeza, subscrita pelos tribunais, de que basta dar pão, como registram Cury et al. (2000, p. 85):

Não basta pôr um ser biológico no mundo. É fundamental complementar sua criação com a ambiência, o aconchego, o carinho, o afeto indispensáveis ao ser humano, sem o que qualquer alimentação, medicamento ou cuidado se torna ineficaz. O ideal é que os filhos sejam planejados e desejados por seus pais e que estes possam garantir-lhes a sobrevivência nas condições adequadas. É fundamental, pois, que os adultos que gerarem a criança a assumam e adotem. A família é o lugar normal e natural de se efetuar a educação, de se aprender o uso adequado da liberdade e onde há a iniciação gradativa no mundo do trabalho. É onde o ser humano em desenvolvimento se sente protegido e de onde ele é lançado para a sociedade e para o universo.

\section{Notas conclusivas}

Julgamentos que dizem respeito às relações familiares devem levar em conta o texto jurídico e o contexto jurídico-social. Assim, em casos como o aqui focalizado, protagonistas emprestam sua história e, com coragem, abrem mão de sua privacidade, tornando pública a sua tragédia pessoal para contribuir com o avanço das discussões. É o que ocorreu, recentemente, no Superior Tribunal de Justiça (STJ), com o julgamento da demanda de reparação por danos morais protagonizada por um filho afetivamente abandonado pelo pai. Nesse julgamento, foi reformada a decisão do Tribunal de Justiça de Minas Gerais (à época, Tribunal de Alçada de Minas Gerais), que havia concedido indenização de 200 salários mínimos ao filho. Histórias de pais "abandônicos" têm sido repetidas, quase um "lugar-comum" para centenas ou milhares de crianças: o casal se separa, uma das partes vai viver outra relação amorosa, constitui nova família e encontra muitas justificativas para não estar mais presente na vida dos/as filhos/as do relacionamento anterior. Pais que não se comprometem com seus filhos/as, empurrando para a mãe a função paterna, etc. 
Nesse caso, o abandono era "apenas" afetivo. O pai sempre pagou pensão alimentícia ao menor, deduzindo-se daí, a inexistência de conduta que trouxesse dor e dano moral ao filho. Faltou, entretanto, alimento para a alma. Afinal de contas, nem só de pão vive o homem. A ausência de prestação de uma assistência material seria até compreensível, caso se tratasse de um pai desprovido de recursos. O amor, o afeto, a convivência não são "itens opcionais de uma engrenagem". São deveres atrelados à paternidade que foram violados frontalmente, configurando-se em atos ilícitos.

A importância desse caso transcende a esfera particular e traz novas reflexões ao Direito: um pai (ou uma mãe) que se nega a conviver com seu filho menor, não lhe dando afeto, está infringindo a lei e deve, ou pode, ser punido por essa falta? Para o exercício do poder familiar (conjunto de direitos e obrigações dos pais com relação aos filhos menores, Art. 1.634 do Código Civil Brasileiro) a legislação deixa claro quais são os deveres dos pais, sobre os quais o STJ não colocou dúvidas. A razão denegatória do STJ ao pedido do filho se apóia na afirmação de que não se pode coagir um pai a amar seu filho. Entendemos que a desatenção, a rejeição, o desafeto devem sofrer sanções, sob o risco de o filho vir a ser titular de direitos reconhecidos, mas vazios e inexigíveis. Além disso, se um pai ou uma mãe não quiser cuidar, dar atenção, carinho e afeto àqueles que trouxeram ao mundo, essa recusa e essa negligência implicam danos à personalidade, os quais devem ser ressarcidos para provocar reflexões e coibir práticas semelhantes.

Afinal, eles são os responsáveis pelos filhos e isso constitui um dever dos pais e um direito dos filhos. O descumprimento dessas obrigações significa violação a direitos do filho. Se os pais que desrespeitarem direitos do filho devem responder por isso, a reparação monetarizaria o afeto? De maneira alguma. O valor da indenização é simbólico e tem apenas função punitiva e educativa. Afinal, não há dinheiro que pague o dano e a violação dos deveres morais à formação da personalidade de um filho abandonado ou rejeitado pelo pai. 
O sofrimento faz parte da vida e os adultos são responsáveis por seus encantos e desencantos amorosos. Os pais são responsáveis pela educação de seus filhos - aí pressupondo-se, cuidados, afeto, apoio moral, atenção. Abandonar e rejeitar um filho é violar direitos. A toda regra jurídica deve corresponder uma sanção, sob pena de se tornar somente regra moral. Uma das razões da existência da lei jurídica é obrigar e colocar limites.

Admitindo-se não ser possível obrigar ninguém a dar afeto, a única sanção possível é a reparatória. Não estabelecer tal sanção aos pais significa premiar a irresponsabilidade e o abandono paterno. Podemos esperar que, proximamente, em casos semelhantes, o Judiciário promova julgamentos alicerçados em novos paradigmas, traduzindo as concepções de uma justiça contemporânea e consolidando o afeto como um valor jurídico, um pressuposto para o exercício da autoridade e das funções paternas.

\title{
Nota
}

1 TJRJ, $4^{\mathrm{a}} \mathrm{CC}, \mathrm{AC} \mathrm{n}^{\mathrm{o}}$ 2004.001.13664, rel. Des. Mário dos Santos Paulo, j. 8/9/2004.

\section{Man shall not live by bread alone}

\begin{abstract}
The present article contributes to the discussions regarding the prerrogatives of paternity, under the aspect of valueing paternal functions, the limitation of rights and the affirmation of the paternal duties. A provocative polemic has been installed stemming from the eclosion of judicial demands in which children denounce the affective, psychic and moral abandon suffered from their fathers, claiming reparations for damages caused, all in court. Some of the children demand financial remunerations to compensate affective abandon. Others, claiming that a father can't be forced to love or live with a child, oppose claiming for financial compensations. They state that, once living up to the function of providing alimony, a father would be exempt from his obligations towards the child. However, a person needs more than bread to survive...
\end{abstract}


Key-words: fatherhood, emotional distress, affection as a juridical value, reparation.

\section{Referências bibliográficas}

ALVES, Rubem. Um mundo num grão de areia: o ser humano e seu universo. Campinas: Verus, 2002.

CURY, Munir; SILVA, Antônio Fernando do Amaral; MENDEZ, Emílio Garcia (Coord.). Estatuto da Criança e do Adolescente comentado. 3. ed. São Paulo: Malheiros, 2000.

JURITSCH, Martim. Sociologia da paternidade: o pai na família e no mundo: uma análise antropológica. Trad. João Batista Quaini. Petrópolis:Vozes, 1970.

MORAES. Maria Celina Bodin de. Deveres parentais e responsabilidade civil. Revista Brasileira de Direito de Família, Porto Alegre, Síntese-IBDFAM, v. 31, ago./set. 2005.

OLIVEIRA, José Sebastião de. Fundamentos constitucionais do direito de família. São Paulo: Editora Revista dos Tribunais, 2002.

TEIXEIRA, Ana Carolina Brochado. Responsabilidade civil e ofensa à dignidade humana. Revista Brasileira de Direito de Família. Porto Alegre, Síntese-IBDFAM, v. 32, out./nov. 2005. 